\title{
RECEIVED
}

SFP 231996

OSTI

LS-150 (ANL)

H. Bizek and W. Chou

June 6,1990

\section{Study of Transverse Loss Factor for the Tapered Sections in the APS Storage Ring}

\section{Transverse loss factor power law}

In the 7-GeV Advanced Photon Source (APS) storage ring, the tapered sections are considered to be the main contributor to the transverse impedance. The structure is shown in Fig. 1. The large tube represents the beam chamber, and the small one the insertion device (ID) section. Both are connected by a tapered transition with angle $\theta$. This note presents a power law dependence of the transverse loss factor on the taper angle for this structure.

We define a normalized taper angle $\phi$ by

$$
\phi=\theta / 90^{\circ},
$$

which is dimensionless and varies between 1 and 0 when the transition length $L$ changes between 0 and infinity. The power law can be expressed as

$$
k(\phi)=B \phi^{\alpha},
$$

in which $k$ is the transverse loss, and $B$ and $\alpha$ are two parameters. Both $B$ and $\alpha$ are functions of the bunch length $\sigma$ and the tube radii $a$ and $b$. When $\phi=1$, which corresponds to a step-like discontinuity, the loss is equal to $B$. This value can be accurately computed by TBCI. [?] It has a dimension of $V / p C \cdot m$, same as that of $k$.

To illustrate this law, we start with the parameters of the transition from chamber to ID section in the APS storage ring.

$$
\begin{aligned}
\sigma & =0.58 \mathrm{~cm}, \\
b & =0.4 \mathrm{~cm}, \\
a & =2 \mathrm{~cm} .
\end{aligned}
$$

Fig. 2 shows a plot of the transverse loss factor $k$ versus the normalized taper angle $\phi$ for this case. The solid curve represents the power law with $\alpha=0.756$ and $B=369.1 \mathrm{~V} / \mathrm{pC} \cdot \mathrm{m}$. The diamond-like points represent data calculated by TBCI, which fits very well to the curve.

When the geometrical parameters $a$ and $b$ and the bunch length $\sigma$ change, $B$ and $\alpha$ will change accordingly. Table 1 is a list that summarizes our results. In No. 1-5, the 


\section{DISCLAIMER}

Portions of this document may be illegible in electronic image products. Images are produced from the best available original document. 
bunch is relatively long, $(\sigma=0.58$ or $1.16 \mathrm{~cm})$ Eq. (2) works well for various values of $a$ and $b$. Fig. 3 is another example (No. 2 in Table 1 ), in which $b$ is increased to $0.5 \mathrm{~cm}$. In No. 6 , however, we find that the power law doesn't fit too well for short bunches, $(\sigma=0.29 \mathrm{~cm})$ as seen in Fig. 4. This may be attributed to the errors in TBCI data, which is to be discussed in the following section.

\section{Errors in TBCI output and two correction schemes}

When we employ TBCI to calculate the wake potentials for this type of structure, "humps" are often observed in the output. Namely, near the bunch head, the transverse wake becomes negative whereas the longitudinal and azimuthal ones become positive, as shown in Fig. $\check{5}(\mathrm{a})$ and $6(\mathrm{a})$. These results are apparently nonphysical. We have used two schemes to get rid of these humps. Both seem to work.

(a) Reducing mesh size:

Fig. 5 shows the wake potentials calculated by TBCI for a $0.58 \mathrm{~cm}$ bunch traversing the tapered section. The calculation has been done for mesh sizes $\delta$ ranging from $0.1 \mathrm{~cm}$ down to $0.0125 \mathrm{~cm}$, corresponding to the number of mesh points from approximately 10,000 up to 600,000 . The humps are clearly visible in Fig. 5(a) $(\delta=0.1 \mathrm{~cm})$, while practically non-existent in Fig. $5(\mathrm{~b})$ $(\delta=0.0125 \mathrm{~cm})$. This is due to the fact that TBCI is a "first-order" code, that is, all variables in the Maxwell equations are expanded to first-order terms. The second-order errors contribute to the nonphysical hump, and they will get smaller with decreasing mesh size.

(b) Invoking WAKCOR:

Another way to "iron out" the humps is to make use of WAKCOR, a postprocessor of TBCI. This is similar to the so-called direct method. It involves three runs.

i. Use TBCI to get the wakes $W^{(1)}$ (Fig. 6(a)) for the structure shown in Fig. 1.

ii. Use TBCI to get the error wakes $W^{(2)}$ (Fig. 6(b)) for a smooth tube as shown in Fig. 7. The integration should be performed along the same path as that in the previous run, i. e., a distance of $b$ from the axis.

iii. Use WAKCOR to subtract $W^{(2)}$ from $W^{(1)}$ to get the corrected wakes $W^{(3)}$ (Fig. 6(c)). The humps become much less pronounced.

The explanation is as follows. $W^{(1)}$ includes both the true wakes and the error parts, while $W^{(2)}$ has error parts only. When we do the subtraction, most errors in $W^{(1)}$ are gone, resulting in more accurate wakes.

\section{Conclusions}

We have numerically found a power law, Eq. (2), which can describe the dependence of the loss $k$ to the taper angle $\theta$ (at least for the not-so-short bunches). Due to the fact 
that TBCI uses only three types of angles $-0^{\circ}, 45^{\circ}$ and $90^{\circ}$ - the matching between the actual boundary and the TBCI-generated one would be poor when the taper angle in Fig. 1 is far away from these values. For example, $\theta$ of the APS storage ring is just about $5^{\circ}$, which leads to slow convergence of TBCI results. [2] Therefore, the following recipe based on Eq. (2) should prove useful.

- For given parameters $\sigma, a$ and $b$, calculate $k$ using TBCI when $\theta=90^{\circ}$. It is equal to $B$.

- Calculate $k$ when $\theta=45^{\circ}$, which determines $\alpha$.

- Obtain $k$ for any given $\theta$ from Eqs. (1) and (2).

The two schemes discussed in Sec. 2 are useful to get more accurate results from a TBCI output.

At this moment, it is not clear to us how truthful this power law is. Our results are solely numerical. However, it is unlikely that the good agreement between the TBCI data and the power law curve is coincidental. It is planned to attempt to derive a proof by using the recently developed method of boundary perturbation. [3]

\section{References}

[1] T. Weiland, Nuclear Instruments and Methods, V 212, p 13 (1983).

[2] W. Chou and H. Bizek, Impedance and Bunch Lengthening in the APS, in Workshop Proceedings on Impedance and Bunch Instability, Oct 31 - Nov 1, 1989, Argonne National Laboratory.

[3] W. Chou, The method of Boundary Perturbation, and Its Application to Wakefield Calculations, Argonne National Laboratory, Light Source Note LS- (1990) (pending for approval). 
TABLE I

Transverse Loss Eactor Power Iaw

\begin{tabular}{|c|c|c|c|c|}
\hline No. & $(a, b)$ in $\mathrm{cm}$ & $\sigma$ in $c$ & $B$ in $V / g C \cdot \pi$ & $c$ \\
\hline $\begin{array}{l}1 \\
2 \\
3 \\
5\end{array}$ & $\begin{array}{l}(2,0.1) \\
(2,0.8) \\
(2,1.6) \\
(1,0.4)\end{array}$ & $\begin{array}{l}0.53 \\
0.55 \\
0.53 \\
0.53\end{array}$ & $\begin{array}{l}360.1 \\
128.1 \\
10.17 \\
230.0\end{array}$ & $\begin{array}{l}0.755 \\
0.753 \\
0.573 \\
0.672\end{array}$ \\
\hline j & $\therefore \quad(2,0.4)$ & 1.16 & 16.7 & 0.700 \\
\hline 6 & $\left(2,0 . \frac{1}{2}\right)$ & 0.29 & 655.5 & 0.651 \\
\hline
\end{tabular}

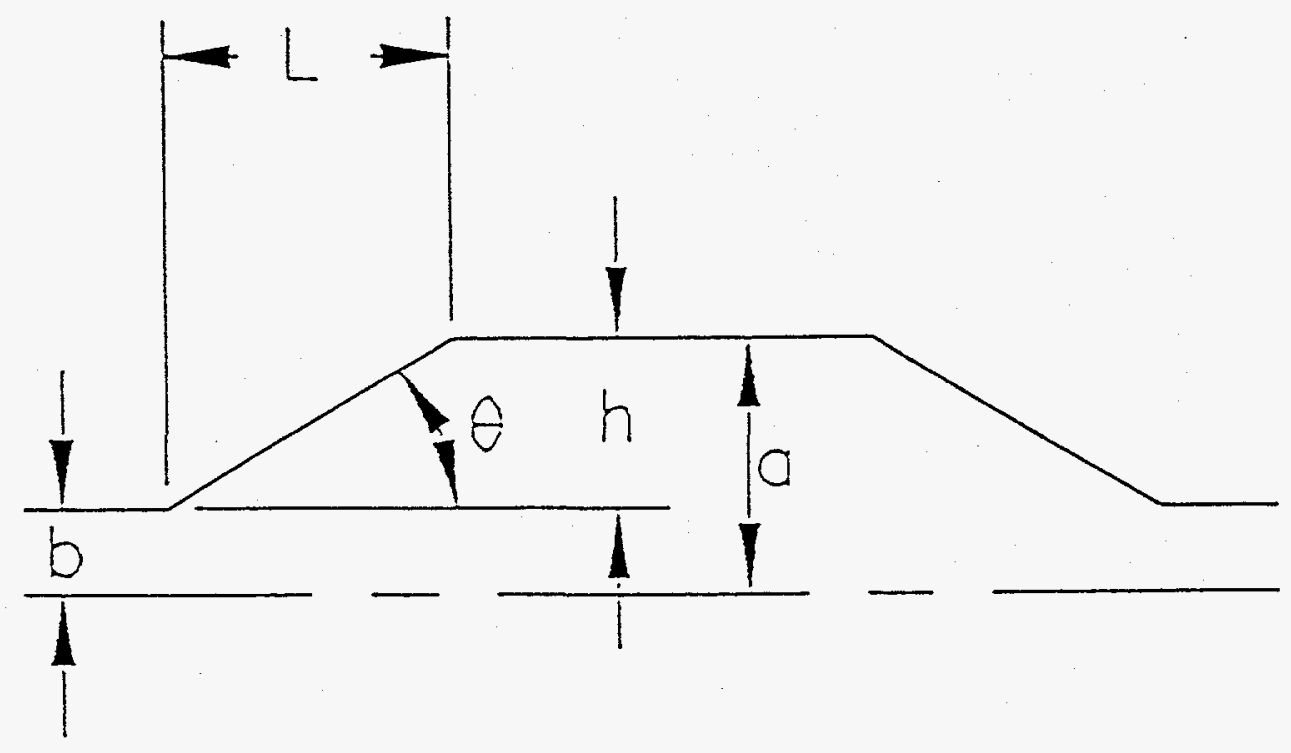

Figure 1. Tapered sections in the APS storage ring. 


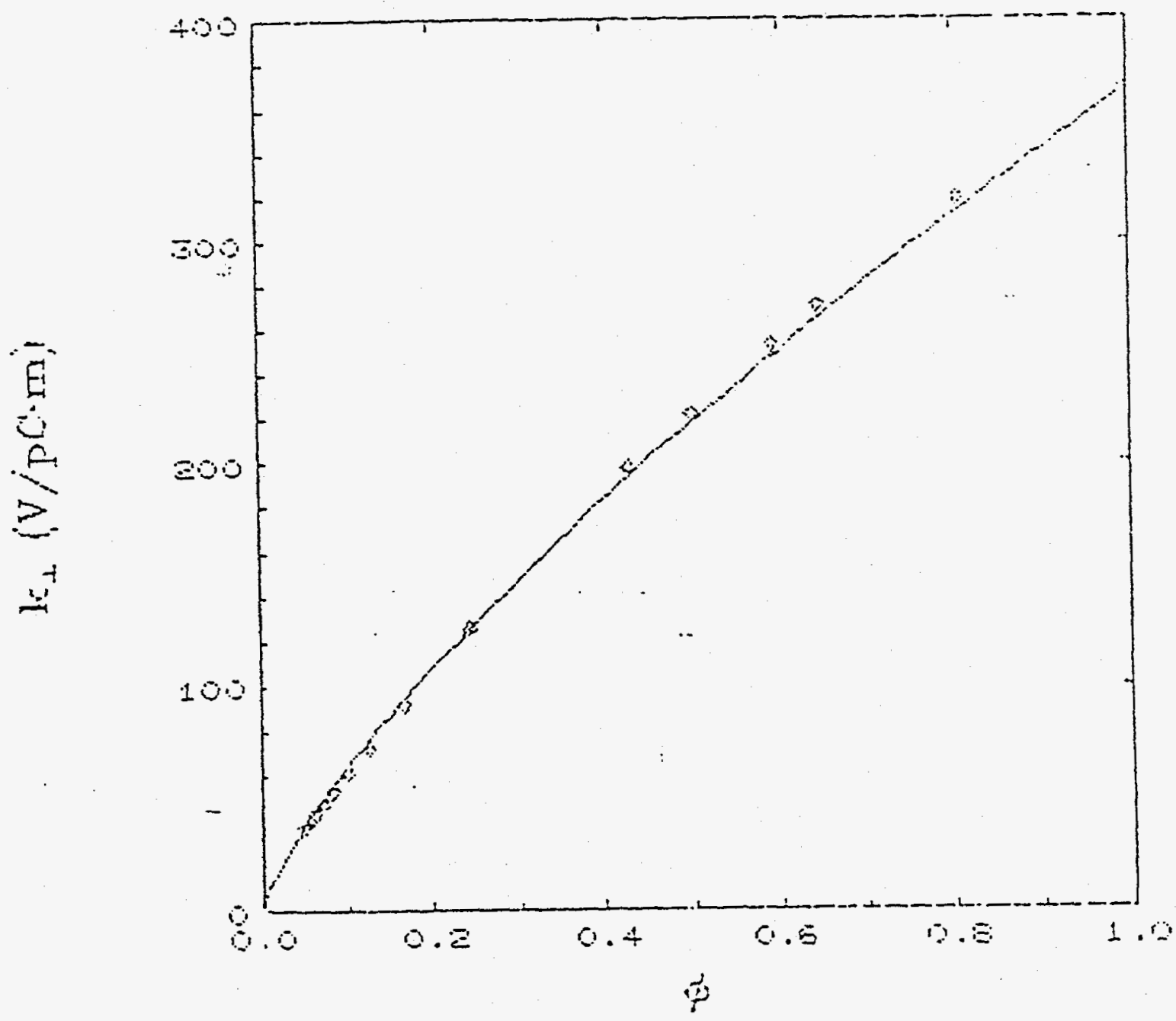

Figure 2. Transwerse loss factor power law for $a=2 \mathrm{~cm}, b=0.1 \mathrm{~cm}, \sigma=0.58 \mathrm{~cm}$. 


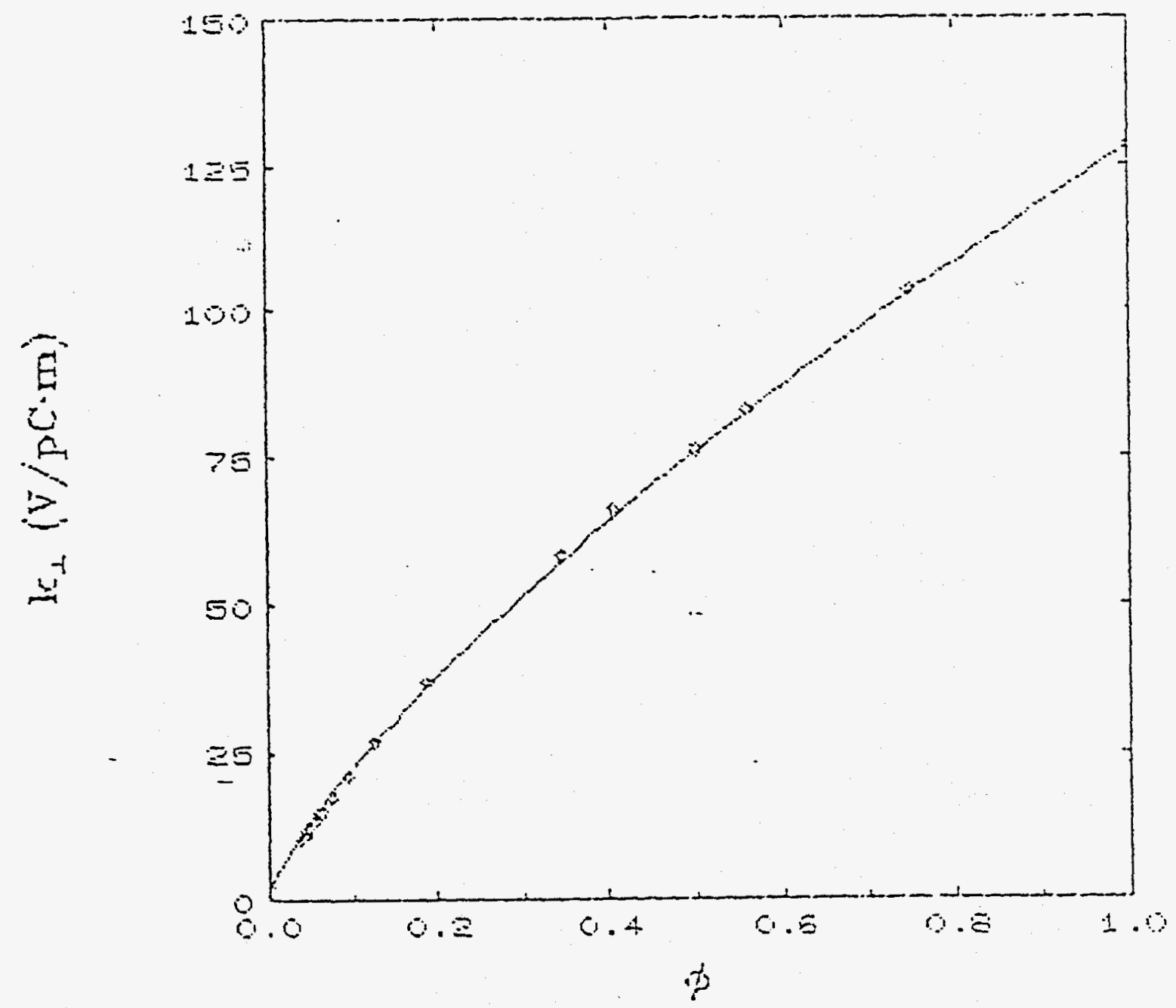

Figure 3. Transverse loss factor power law for $a=2 \mathrm{~cm}, b=0.8 \mathrm{~cm}, \sigma=0.38 \mathrm{~cm}$. 


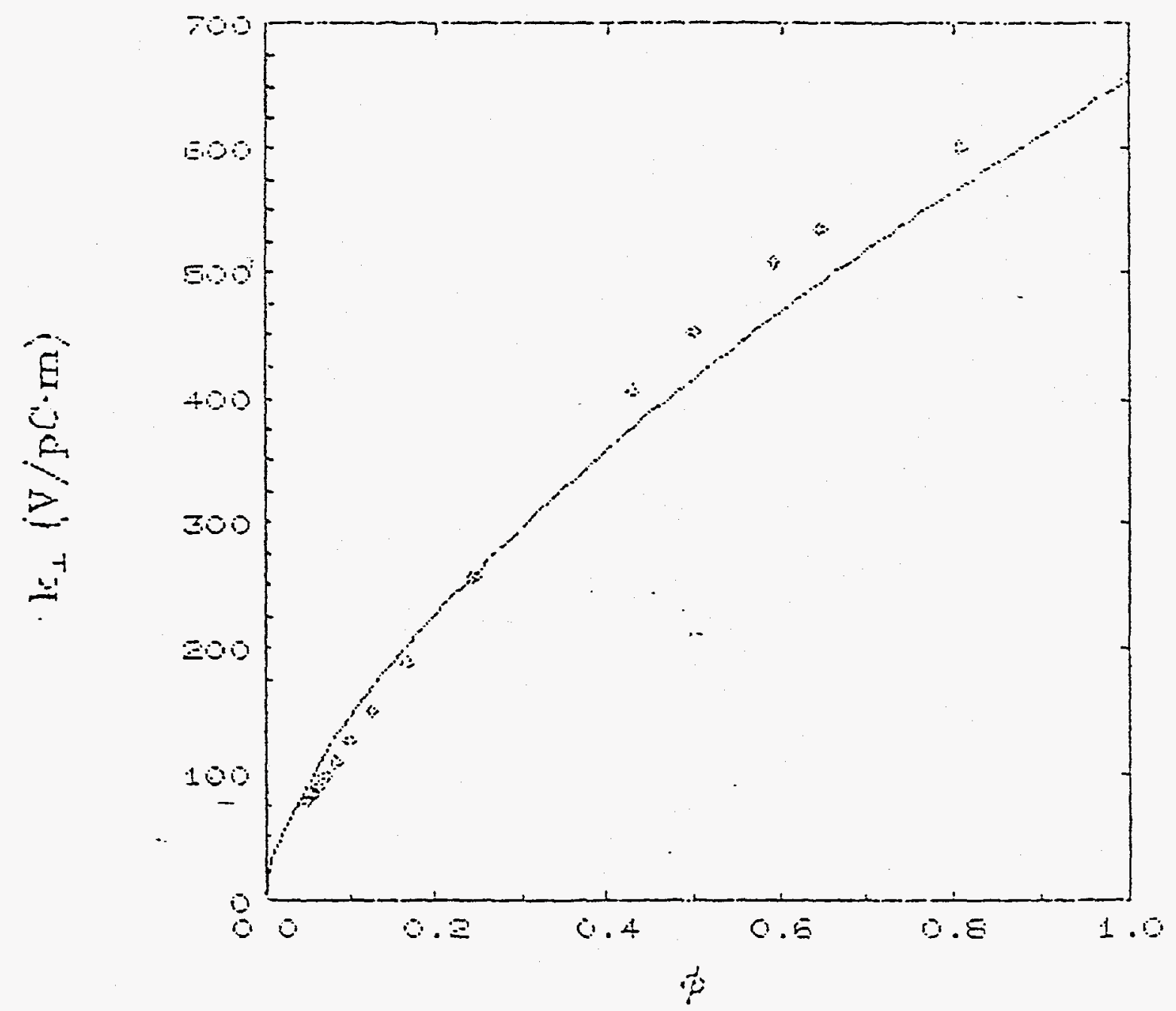

Figure 4 . Transverse loss factor power law for $a=2 \mathrm{~cm}, b=0.4 \mathrm{~cm}, \sigma=0.29 \mathrm{~cm}$. 

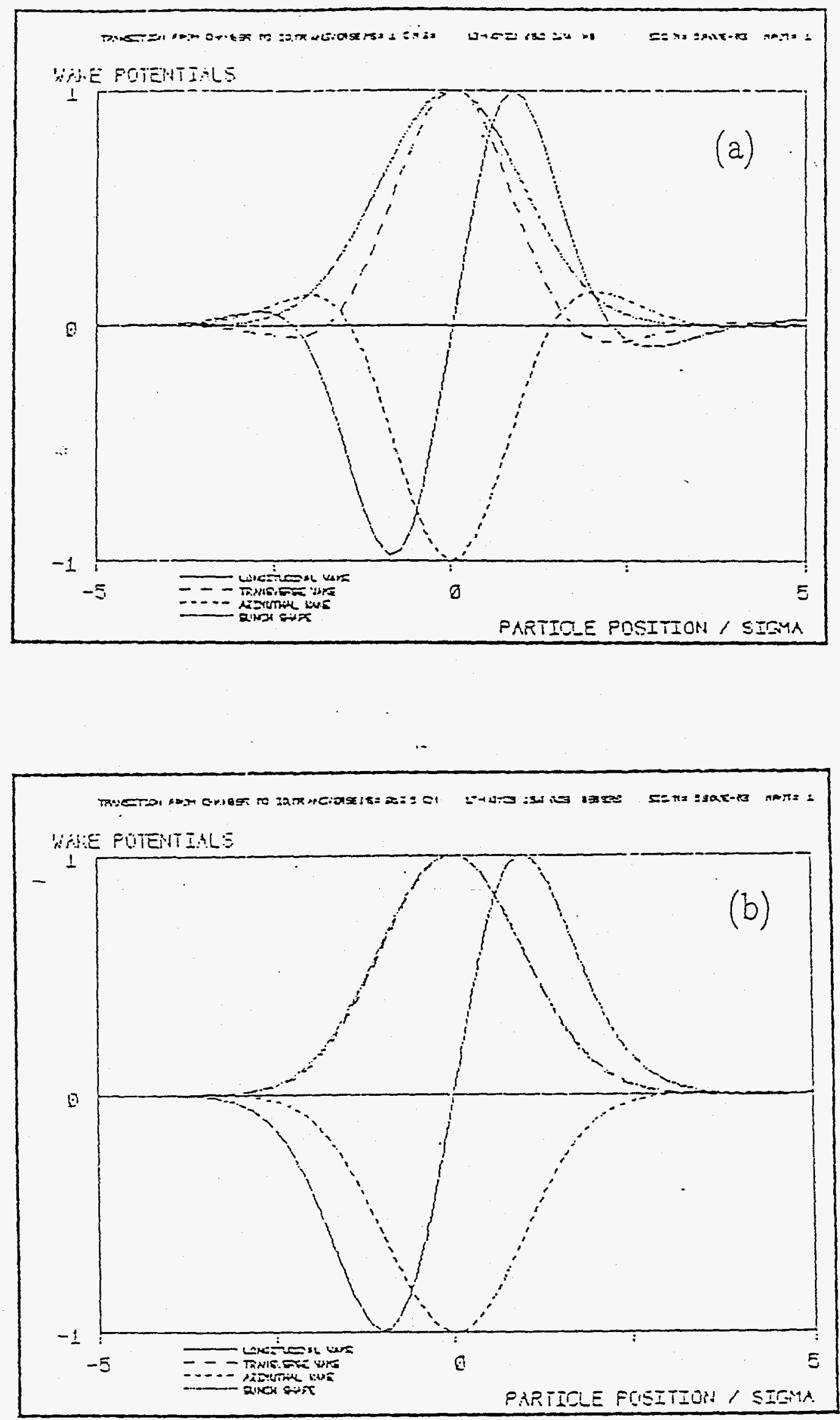

Figure 5. TBCI correction via decreased mesh size. 

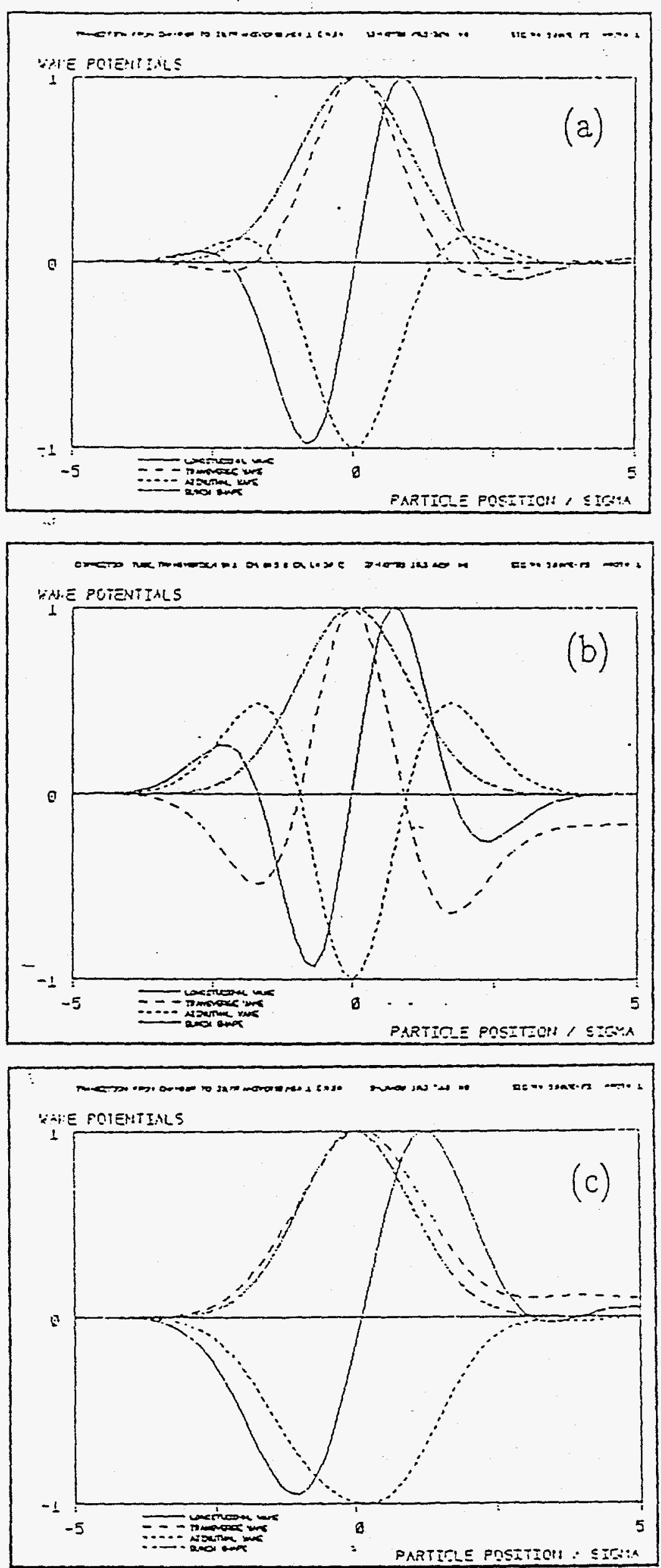

Figure 6. TBCI correction via WAKCOR. 


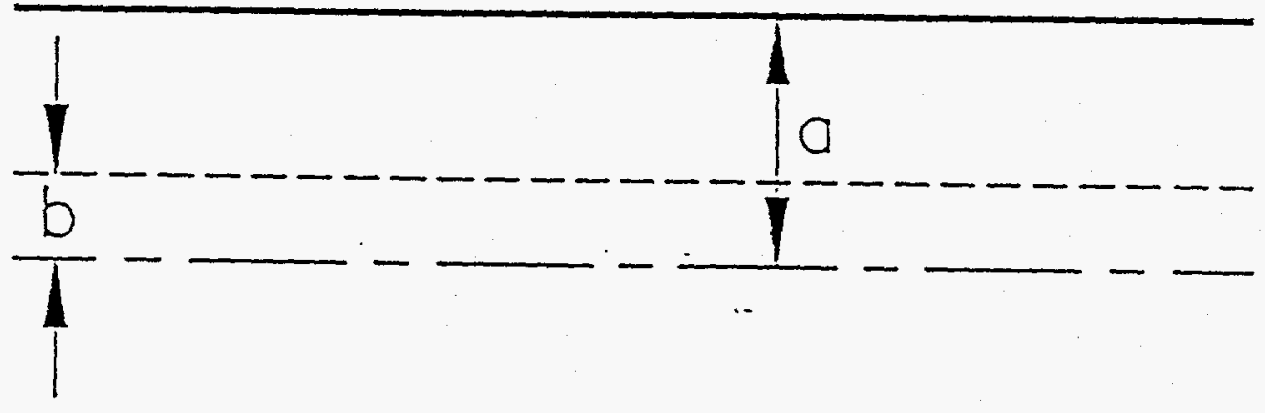

Figure T. The smooth tube used in WAKCOR correction. $\cdots$

\section{DISCLAIMER}

This report was prepared as an account of work sponsored by an agency of the United States Government. Neither the United States Government nor any agency thereof, nor any of their employees, makes any warranty, express or implied, or assumes any legal liability or responsibility for the accuracy, completeness, or usefulness of any information, apparatus, product, or process disclosed, or represents that its use would not infringe privately owned rights. Reference herein to any specific commercial product, process, or service by trade name, trademark, manufacturer, or otherwise does not necessarily constitute or imply its endorsement, recommendation, or favoring by the United States Government or any agency thereof. The views and opinions of authors expressed herein do not necessarily state or reflect those of the United States Government or any agency thereof. 